\title{
Ulrike Landfester
}

\section{Der Autor als Stifter oder Die Mappe meines Urgroßvaters}

In der frühesten Fassung von Adalbert Stifters Die Mappe meines Urgroßvaters trägt das Buch, in dem der Ich-Erzähler der Rahmenhandlung auf die Lebensaufzeichnungen seines Urgroßvaters stößt, den Titel „Memorabilia und seltene casus aus dem Leben und praxi M. Dr. Augustini Fundatoris"., Das Spiel mit dem eigenen Namen, die Latinisierung von ;Stifter ${ }^{\star} \mathrm{zu}$,Fundator', legt eine Spur, die Stifter in den späteren Fassungen durch Auslassung des Nachnamens zurïcknimmt, um das Spiel selbst desto entschiedener zu erweitern: In Die Mappe meines Urgroßvaters wird der Begriff des Stifters im Sinne des von der Journalfassung eingeführten ,Fundator' von dieser ersten über die Buchfassung bis hin zur unvollendeten dritten und schließlich der letzten, nach dem Tod Stifters 1868 ebenfalls Fragment gebliebenen Fassung immer offensichtlicher zum Schlüsselbegriff eines poetologischen Diskurses, in dem Tradition und gesellschaftlicher Auftrag des Stiftungswesens zugleich Inzitament und Medium literarischen Ringens um die Bestimmung auktorialen Selbstverständnisses sind.

Stifters Kunstreflexion entwickelt in dem Maß, in dem sie zunehmend von kulturpolitischen Zielsetzungen bestimmt wird, eine Affinität zu jener Verschränkung privater Initiative mit öffentlichem Nutzen, die das Stiftungswesen seit seinen Anfängen im vorklassischen Altertum kennzeichnet. ${ }^{2}$ Schon Stifters grundlegende Überzeugung von der religiösen Verfaßtheit jeder Kunst - „,Religion und Kunst", so schreibt er etwa an Auguste von Jäger am 20. Dezember 1852, ,in höchster Stufe in Eins zusammen fallend sind das einzige Gut des Menschen, alles, Wissenschaft Gewerbe der Staat selbst sind nur Mittel" ${ }^{\text {‘3 }}$

1 Nachweise für Zitate aus den vier Fassungen von Die Mappe meines Urgroßvaters werden mit römischen Zifferm für die verschiedenen Fassungen und Seitenzahl im laufenden Text angeschlossen. Die Ziffern beziehen sich auf folgende Textausgaben: I: HKG 1,2, S. 9102; II: HKG 1,5, S. 9-234; III: HKG 6,1; IV: PRA 12. Hier: I, 13.

2 Zur Geschichte des Stiftungswesens vgl. Joachim Fest: Einführung. In: Joachim Fest (Hrsg.): Die großen Stifter. Lebensbilder - Zeitbilder. Berlin 1997, S. 7-24, sowie Carola Jäggi und Hans-Rudolf Meier: Einleitung. In: Hans-Rudolf Meier u. .a. (Hrsg.): Für irdischen Ruhm und himmlischen Lohn. Stifter und Auftraggeber in der mittelalterlichen Kunst. Berlin 1995, S. 9-30.

3 PRA 18, S. 127. 
steht der ursprünglich stiftungstypischen Pflege von religiösen Kulten und Ahnenverehrung nahe, weist er doch bereits 1830 den Bruder seiner Jugendgeliebten Fanni, Matthias Greipl, im Sinne solcher Ehrung nachdrücklich auf die Literatur als Mittel zur Selbstbildung hin: „Du klagst über Mangel an Umgang, gehe mit erhabenen Todten um, die durch ihre Schriften mit dir sprechen. Edle Dichter, große Geschichtsschreiber, [...] gründliche Denker sind eine heilige und freundliche Gesellschaft." 4

Vor allem jedoch der Aspekt der caritas, der mit Ausbreitung des Christentums die soziale Funktion des Stiftungswesens nach Maßgabe des Gebots der Nächstenliebe modifizierte, besitzt für Stifters Auffassung vom gesellschaftlichen Auftrag des Schriftstellers entscheidendes Gewicht. Literatur gilt ihm als ein Instrument zur Bildung des Lesers, nicht auf dem Weg polemischer Didaktik, sondern durch die Darstellung des Schönen als Ausdruck sittlicher Gesetzmäßigkeit, die den Leser über den Reiz des Schönen dazu verführt, sich lesend selbst zur Sittlichkeit zu erziehen. ${ }^{5}$ In dieser Haltung propagiert er sein Leben lang als Autor, als Funktionär des Schulwesens und als Vizepräsident des 1851 gegründeten Oberösterreichischen Kunstvereins mit unerschütterlichem Sendungsbewußtsein die Bildung des Menschen durch Kunst: "[...] was mir das Höchste Herrlichste Wünschenswertheste dieses Lebens erscheint,“ schreibt er am 29. Juli 1858 an seinen Verleger Gustav Heckenast, „[...] die Vernunftwürde des Menschen in seiner Sitte in seiner Wissenschaft in seiner Kunst, soll dauern soll verehrt werden, und soll die reinste Herrschaft führen. Dies stirbt nicht, dies gründen zu helfen, die auszubreiten erscheint mir ein unsterbliches ein glükseliges Leben [...].“"

Setzt Stifter schon hier das Wort, gründen' dazu ein, Anspruch auf Teilhabe an der ,Herrschaft' menschlicher, Vernunftwürde' zu erheben, so verwendet er dort, wo er konkret von der Aufgabe des Schriftstellers spricht, immer wieder auch explizit das Wort ,stiften'. So erklärt er in einem Brief an Heckenast am 9. Januar 1845 in nachdrücklicher Abgrenzung von den Bemühungen des ,Jungen Deutschland', die politische Bildung des zeitgenössischen Lesers durch Integration von „Tagesfragen, und Tagesempfindungen in die schöne Litteratur" zu betreiben, er sei der Ansicht,

[...] daß das Schöne gar keinen andern Zwek habe, als schön zu sein, und daß man Politik nicht in Versen und Deklamationen macht, sondern durch wissenschaftliche Staatsbildung, die man sich vorher aneignet, und durch zeitbewußte Thaten, die man nachher sezt, seien

4 3. Juli 1830 (PRA 17, S. 25).

5 Zu Stifters pädagogischem Konzept vgl. Kurt Gerhard Fischer: Die Pädagogik des Menschenmöglichen. Adalbert Stifter. Linz 1962; Fischer weist zu Recht auf die Unmöglichkeit hin, ,aus Stifters Denken und Dichten eine formelhafte Definition eines Bildungsideales abzuleiten. [...] Seine Sorge war nicht ein unerreichbares Ideal, sondern die Wahrung des Begriffes der Bildung" (S. 635); sowie in letzter Zeit Walter Seifert: „Literaturidee und Literaturdidaktik bei Adalbert Stifter". In: Hartmut Laufhütte und Karl Möseneder (Hrsg.): Adalbert Stifter: Dichter und Maler, Denkmalpfleger und Schulmann. Neue Zugänge zu seinem Werk. Tübingen 1996, S. 157-184. 
sie in Schrift, Wort oder Werk. Solche Thaten dann, die aus der Wärme des Herzens und aus der Competenz des Kopfes hervorgehn, werden jederzeit ein Gutes stiften wenn sie auch ohne sichtbare unmittelbare Folge bleiben. ${ }^{7}$

Ganz ähnlich formuliert er in seinem Aufsatz Ueber Stand und Würde des Schriftstellers im Revolutionsjahr 1848, der Literaturschaffende habe die ,heilige Pflicht", seiner Begabung durch ausgedehnten Wissenserwerb sowie dadurch, „daß er seinen Charakter zu der größtmöglichsten Reinheit und Vollkommenheit heranbilde", das doppelte Fundament wissenschaftlicher und moralischer Integrität zu verleihen, damit er keinesfalls „durch das glänzende Schwert seiner Rede leichtsinnig Irrtum verbreitet und Unheil stiftet".8

So wenig zufällig die Wahl des Worts ,stiften' zur Beschreibung der Gelenkstelle ist, über die der Schriftsteller mit seinem Werk in die Wirklichkeit eingreift, so wenig zufällig ist auch der Gebrauch des Wortstammes ,Heil', wie er schon in der , heiligen Gesellschaft' der Greipl anempfohlenen verstorbenen Dichter und hier erneut in der Gegenüberstellung von ,heiliger Pflicht" und ,Unheil' aufscheint. Formulierungen wie die, in der Stifter 1858 gegenüber Heckenast seine pädagogischen Anstrengungen mit der Hoffnung auf ,ein unsterbliches Leben" verknüpft, um im weiteren Verlauf des Briefes die ,Vernunftwürde“ sogar als „das irdische Reich Gottes die irdische Ewigkeit“9 $\mathrm{zu}$ verklären, stellen eine Verwandtschaftsbeziehung zwischen der Motivation von Stifters literarischem Bildungsprojekt und jenem Heilsstreben her, das das Motivspektrum christlich-abendländischer Stiftungsunternehmungen seit dem frühen Mittelalter dominiert. Die Erscheinungsform solchen Heilsstrebens bei Stifter legt dabei Zeugnis für den Entwicklungsstand des Stiftungswesens im 19. Jahrhundert $a b$, gelangt es doch als säkularisierte caritas zum Austrag, als ein den humanistischen Idealen der Spätaufklärung verpflichtetes Modell ethisch-moralischer Fürsorge, das, in seinen Verfahren geprägt von den Errungenschaften moderner Naturwissenschaften, ,Heil' weniger in der Hoffnung auf jenseitiges Seelenheil als vielmehr in der diesseitigen Heilung von Übelständen aufsucht, im ,irdischen Reich Gottes` also, für das der Dichter mit den von ihm verfaßten Werken eine dem Arztberuf analoge Funktion erfüllt: „Bücher“, schreibt Stifter am 18. April 1847 an Heckenast, „werden gerade so gesucht, wenn man den Verfasser kennt und liebgewinnt, wie ein Arzt, dessen Person in vielen Gesellschaften gekannt und geliebt ist." 10

Deutet schon diese Parallelisierung medizinischer und poetischer Heilungsverfahren auf ein zentrales Motiv der Mappe, so sind darüber hinaus zwei Tatbestände festzuhalten, die der Mappe im Gefüge von Stifters Kunstauffassung eine besondere Rolle zuweisen. Zum einen kristallisiert sich die oben skizzierte Affinität von Autorschaft und Stiftungswesen erst während Stifters

PRA 17, S. 138f.

8 Ueber Stand und Würde des Schriftstellers. HKG 8,1, S. 34-46. Hier: S. 37f.

9 PRA 19, S. 129.

10 PRA 17, S. 216. 
Arbeit an der Mappe heraus, zu einem Zeitpunkt nämlich, zu dem er mit der Umgestaltung der Journalfassung zur Buchfassung befaßt war. Noch auffälliger aber ist es zum anderen, daß Stifter die Mappe als einziges seiner Werke im Verlauf dieses Arbeitsprozesses mehrfach betont mit dem Begriffsfeld des ,Heils' in Verbindung bringt, einmal, indem er Heckenast am 1. April 1845 erklärt, die Mappe sei ihm „eine Art Heiligthum",11 und ein zweitesmal nach Erscheinen der Buchfassung am 16. Februar 1847, als er ebenfalls Heckenast gegenüber unzufrieden feststellt, in ihrer vorliegenden Gestalt sei die Mappe „eine heillose Geschichte". 12

Die Bedeutung dieser Bemerkungen erhellt aus den Zeugnissen zur Entstehungsgeschichte der Buchfassung. Stifters Briefe darüber an Heckenast dokumentieren ein fast obsessives Engagement bei der Um- und Neuschrift ganzer Kapitel, das selbst für ihn, der bis an das Ende seines Lebens noch bei der Druckfahnenkorrektur immer wieder extensive inhaltliche Eingriffe in seine Texte vornahm, ungewöhnlich war, ging er doch einmal dabei sogar so weit, "den $1^{\text {len }}$ Bogen der Mappe, alle Buchstaben zählend, wieder so um zu gießen“, $\mathrm{da}$ er dem bereits gesetzten Text vom Umfang her genau entsprach. ${ }^{13}$ Der Grund für diesen Aufwand wird deutlich, als er am 25. Dezember 1844 zwei neu hinzugekommene Kapitel damit rechtfertigte, „die Erzählung des Obrists“. sei "das erste von mir [...], was man etwa klassisch nennen konnte“.14 Nur wenige Monate später fiel in diesem Zusammenhang dann der Begriff des ,Heiligthums' - bei der Vollendung der Mappe galt es Stifter nicht einfach die Produktion eines unter den sechs Bänden Studien, sondern mit der Anwartschaft auf den Rang ,klassischen' Literatentums eine spezifisch an diesen Text gekoppelte Heilserwartung. Nur widerwillig gab er Ende Mai 1846 dem Drängen Heckenasts auf Ablieferung des Manuskripts nach - ,Alles schwebte mir anders, herrlicher vor. Sollte ich es so ausarbeiten, wie ich wollte, wäre ich noch nicht fertig. In Gottes Namen! Mit wahrer Wehmuth gebe ich das Ding weg"15 - und erklärte angesichts der fertigen Buchfassung mit dem Wort von der ,heillosen Geschichte“ diese Erwartung als für diesmal uneinlösbar: ,[...] wäre es gelungen, dann hätte das Buch mit der Größe, mit der Einfalt und mit dem Reize der Antike gewirkt. - - So aber ist es nicht so [...]". ${ }^{\prime \prime}$ Es sei ein „Bruchstück“ geblieben, „noch nicht aus dem Rohen heraus gearbeitet", und könne daher nur vorübergehend „wie es ist, als eine Studie in den Studien“ stehengelassen werden, bis er eines Tages „das ganze Werk rein gefeilt, geordnet, vollendet und geklart" als „selbständiges Buch"17 vorlegen werde - ein Vorhaben, das letztlich an dem grundlegend aporetischen Konflikt zwischen

Ebd., S. 208.

13 16. November 1846 (PRA 17, S. 182).

14 Ebd., S. 132f.

15 Ebd., S. 165.

16 Ebd., S. 208.

17 Ebd., S. 209f. 
Konstruktionsprinzip und Vollendungsanspruch auf unüberwindliche Grenzen stoßen sollte.

\section{II}

Ist Stifters Erzählungen durchweg gemeinsam, daß in ihnen das, was ,als Motiv, Handlungsmuster oder Figurenkonstellation an der Oberfläche der Texte erscheint, [...] die ins Sichtbare gedrängte Erzählsituation" "18 ist, so gilt diese selbstreferentielle Inszenierung in Die Mappe meines Urgroßvaters von der Journalfassung an ${ }^{19}$ der umfassenden Bestimmung von Bedingungen und Möglichkeiten von Autorschaft. ${ }^{20}$ Mit dem im Text selbst namenlos bleibenden Rahmenerzähler, seinem Urgroßvater, dem Obristen und schließlich dem schriftstellernden Jurastudenten Eustachius verhandelt Stifter vier unterschiedliche Modelle des Schreibens, zu denen sich ab der Buchfassung noch die Hilfskonstruktion vom Vater des Rahmenerzählers gesellt. Allen diesen Modellen liegt ein Paradigma von Autorschaft zugrunde, das Stifter zwischen den beiden einander oppositionell zugeordneten Polen des Autors als Erfinder und des Autors als Kopisten ausfaltet.21 Sein Ziel ist dabei, dem Gestus seines literarischen Bildungskonzepts entsprechend, der Entwurf des idealen Autors im Spannungsfeld zwischen ethisch-moralischer Selbstheilung auf der einen und dem vor allem in Eustachius verkörperten poetischen Schöpfertum auf der anderen Seite. Der Entwurf des Autors als Stifter im Sinne des ,Fundator bezieht aus diesem Spannungsfeld seinen Gehalt, insofern darin nicht nur die Verknüpfung von Schreiben und Heilsstreben ausgetragen wird, sondern auch die Vielfältigkeit der Facetten, in denen sich das Verhältnis eines Stifters zu dem von ihm gestifteten Werk manifestieren kann: in der gesellschaftlichen Funktion des Gründers einer karitativen und/oder kulturellen Institution, in der genealogischen als Stammvater eines Geschlechts, in der wirtschaftlichen als Finanzier und Auftraggeber und in der künstlerischen als Ausführender eines

18 Cornelia Blasberg: Erschriebene Tradition. Adalbert Stifter oder das Erzählen im Zeichen verlorener Geschichten. Freiburg 1998 , S. 31; meine Ausführungen knüpfen insgesamt an den von Blasbergs hochinteressanter Studie bereitgestellten Erkenntnissen vor allem zu den genealogisierenden Textstrukturen in Stifters Werk (S. 33-56) und seiner impliziten Literaturgeschichtsschreibung (S. 81-102) an.

19 Der Vergleich zwischen den verschiedenen Fassungen, wie er im Folgenden angedeutet wird, ist eine auf die hier entwickelte These hin entworfene Skizze und kann keinen Anspruch auf Vollständigkeit erheben. $\mathrm{Zu}$ differenzierten Vergleichen vgl. Jörn Klockow: Studien zum Prosarhythmus. Die vier Fassungen der "Mappe meines Urgroßvaters“ von Adalbert Stifter. Wien 1974, sowie vor allem Friedbert Aspetsberger: „Die Aufschreibung des Lebens. Zu Stifters ,Mappe “". In: VASILO 27 (1978), S. 11-38.

20 Zur Bedeutung von Autorschaft und Erzählerrolle in Stifters Werk insgesamt vgl. Hans Dietrich Irmscher:Adalbert Stifter. Wirklichkeitserfahrung und gegenständliche Darstellung. München 1971, S. 262-294.

$21 \mathrm{Zu}$ dieser Binäropposition vgl. Wolfgang Raible: „Vom Autor als Leser zum Leser als Autor. Literaturtheorie in der literarischen Praxis". In: Poetica 5 (1972), S. 133-151. 
Werks, in der religiösen als Sachwalter und Pfleger eines Venerationskultes in der Erwartung, selbst zu dessen Gegenstand werden zu können, historiographisch als in dem von ihm gestifteten Werk überliefertes Porträt und schließlich in derjenigen Funktion, in der Stifter mit der Mappe auf die literarische Begründung seiner Autorschaft zielt - als Verfasser von Stiftungsurkunden.

Die Rahmenerzählung der Mappe eröffnet das Spiel der Facetten, indem sie die Geschichte der Literatur als eine Geschichte der produktiven Rezeption mit dem einst von Augustinus erbauten Haus in Beziehung setzt: Das in allen vier Fassungen noch vor dem Beginn der eigentlichen Niederschrift eingefügte lateinische Zitat „Dulce est, inter majorum versari habitacula, et veterum dicta factaque recensere memoria“ - ,Süß ist es, in den Wohnungen der Vorfahren zu verweilen und der Ahnen Wort und Tat sinnend zu betrachten ${ }^{` 22}$ - entstammt einer freien lateinischen Bearbeitung der von dem jüdischen Historiographen Flavius Iosephus verfaßten Schrift De bello judaico, die unter dem Namen Egesippus oder Hegesippus aus dem 5. Jahrhundert n.Chr. überliefert ist. ${ }^{23}$ Bereits der Erzähler der Buchfassung führt ausdrücklich „mit dem lateinischen Spruche [...] die Leser in das Buch und mit dem Buche in mein altes fern von hier stehendes Vaterhaus ein" (II, 11), und die beiden späteren Fassungen erweitern die Passage zusätzlich um einen Verweis auf die Voraussetzung dafür, daß̉ der Rahmenerzähler diese Verbindung realisieren kann, auf den Erwerb von Schreibkompetenz: Das Zitat, so vermerkt der Erzähler der dritten Fassung, "spielte einmal eine Rolle in einer meiner Schulauszeichnungen“ und sei ihm „,auch nach der Zeit sehr oft ein[gefallen], wenn ich in den Räumen meines Vaterhauses herum ging" (F3 7), und die letzte Fassung schließlich koppelt die Erinnerung an das Zitat darüber hinaus mit derjenigen an die im Haus aufbewahrten „alterthümliche[n] Dinge“ (IV, 3) - legitimiert durch die Tradition antiker Textbearbeitung im Zeichen der von Egesippus beschworenen ,memoria', führt sich die Mappe in ihrem seit der Buchfassung mit „Die Alterthümer“ überschriebenen ersten Kapitel als Anweisung zur produktiven Rezeption, alterthümlicher Dinge‘ ein.

Mit dem fremdsprachigen Zitat und dem Hinweis auf die zu seinem Verständnis notwendige Schulbildung beginnt die Geschichte von Auffindung, Entzifferung und Wiedergabe von Augustinus' Aufzeichnungen als Inszenierung einer doppelten Lektüre: Gilt das Interesse des Rahmenerzählers dem Inhalt dieser Aufzeichnungen, so wird das des Lesers der Mappe zusätzlich auf die Schwierigkeiten gelenkt, die der Erzähler bei deren Erschließung zu überwinden hat. Zwar hat die Statue der heiligen Margaretha zu dem Zeitpunkt, zu dem die Erzählung beginnt, den Schrecken verloren, der das Kind einst von der näheren Untersuchung ihres Fundaments abhielt, doch stößt der erwachsene

Zur Übersetzung vgl. HKG 1,9, S. 247.

23

Vgl. dazu Moriz Enzinger: „Der Vorspruch in der ,Mappe meines Urgroßvaters“". In: Moriz Enzinger: Gesammelte Aufsätze zur Adalbert Stifter. Wien 1967, S. 379-383, hier S. 380f. 
Rahmenerzähler gleichwohl schon in der Journalfassung an dem Fundament selbst erneut auf Widerstand, entpuppt es sich doch als eine „vernagelte Kiste“, die durch „Zange und Brecheisen" gewaltsam geöffnet werden muß. (I, 13) Von der Buchfassung an verstellt Stifter diesen Weg darüber hinaus mit immer neuen Hindernissen: Da erweist sich das in der Truhe aufgefundene Buch als „Calcaria Doctoris Augustini tom II.“ (II, 25), also als der zweite Band, und der erste bedarf einer weiteren zufälligen Entdeckung; da wird „die Lesung“" der Eintragungen im zweiten Band auch physisch „gleichsam verwehrt; denn immer mehrere der so beschriebenen Blätter waren [...] zusammen gesiegelt" (ebd.); und schließlich findet der Rahmenerzähler „viele zerstreute Blätter und Hefte in dem Buche liegen, die sämmtlich die Handschrift meines verstorbenen Vaters trugen“ (ebd.) und seine Aufmerksamkeit ablenken - „Bevor ich in dem Buche las, wollte ich eher diese Dinge des Vaters anschauen“. (II, 26f.)

Vor allem die ,Dinge des Vaters' dienen der Initiation des Rahmenerzählers in den Umgang mit des Urgroßvaters Calcaria, konfrontieren sie ihn doch beispielhaft nicht nur mit der ganzen Breite des Spektrums zwischen Poesie und Autobiographik, das es später bei der Lektüre des Ur-Buches auszuloten gilt - , ,...] da waren Lieder, ferner Bemerkungen und Abhandlungen - auch ein Mährchen war da - Erzählungen aus seinem Leben - Worte an uns Kinder - ferner ein morsches zerfallendes Kalenderblatt, darauf mit zerflossener entfärbter Dinte geschrieben stand: ,Heute mit Gottes Segen mein geliebter erster Sohn geboren. ““ (II, 27) -, sondern zugleich auch mit jener Struktur des Erzählens, an der der implizite Autor des Textes unter der Maske des reproduzierenden Historiographen die schöpferische Willkür des Dichters ausübt: Ist es das Anliegen des Historiographen, aus der Fülle heterogenen Quellenmaterials das Kontinuum der Geschichte zu konstruieren, so insistieren sowohl Journalals auch Buchfassung auf der fragmentarischen Qualität der vom Erzähler präsentierten Quellen.

Mit der Ahnung, „daß in dieser Art Tagebuch ein kostbar Leben meines Ahnherrn liegen müsse, wie ich es mir schon früher aus den Sagen und Bruchstücken alter Erzähler von ihm zusammenlas“ (I, 13), verankert allerdings schon die Journalfassung diese Qualität vor Beginn der eigentlichen Lektüre in der Haltung des Rahmenerzählers: Erwartet dieser eigentlich ein ,Tagebuch', das den fehlenden Sinnzusammenhang der ,Bruchstücke“ bereitstellt, so legt dann sein Plan, nur eine Auswahl „gewisse[r] Aufsätze des Lederbuches drukken zu lassen" (I, 14), das von ihm unternommene Publikationsprojekt insgesamt auf den Status des Bruchstücks fest. Durchweg legitimiert er sein Vorgehen dabei anhand der Sogwirkung, die, von den mit ,gar seltsame[n] rothe[n] Titel[n]" in einzelne Segmente gegliederten Aufzeichnungen ausgehend, deren neuerliche Fragmentarisierung notwendig mache, angefangen von der an den „liebe[n] Leser“ gerichteten Aufforderung, er möge „freundlich mit mir an einigen Stücken meines Ahnherrn vorüber" (I, 14) gehen, bis in das letzte Kapitel hinein, in dem er bekennt, nach der Geschichte der zwei Bettler habe ihn die Suche nach deren Weiterführung und Abschluß gänzlich von der linea- 
ren Lektüre abgebracht: „[...] ich fing zu blättern an, [...] nicht bedenkend, daß eine Lebensskizze sich nicht so ründen könne, wie Romane, wo sich freylich Alles Verlorene wieder findet. In einem solchen Buche aber ist das Blättern nicht so leicht, wie in einem sauber gedruckten" (I, 68) - der Desorientierungseffekt der „höllischen Handschrift“ (ebd.) überträgt sich wie von selbst in das ,sauber gedruckte' Ergebnis von der Übertragungsarbeit des Rahmenerzählers.

Auch in der Buchfassung wird die Zerlegung des ,Ahnherrn' in einzelne ,Stücke‘ zunächst in die Aufzeichnungen selbst projiziert - „[...] das Lesen ist schwer. Oft ist kein rechtes Ende, oft deutet sich der Anfang nur an, manchmal ist die Mitte der Ereignisse da, oder es ist auch eine unverständliche Krankengeschichte" -, trotz der behaupteten Widerständigkeit dieses Materials aber ist der Rahmenerzähler ohne weiteres in der Lage, dessen Inhalt als ,gewöhnlich, wie bei allen andern Leuten" zu klassifizieren, und enthüllt dann, indem er die Herstellung eines übergreifenden Sinnzusammenhangs aus dem Text hinaus in eine Zukunft verlagert, in der er sein Material ,zu Ende geziffert, und ausgezogen" (II, 232) haben wird, sein Projekt als einen Konstruktionsprozeß, der auf seine eigene Identität als Autor hinzielt. So fällt der Begriff der Mappe, der in der Journalfassung noch den Rahmenerzähler als Auswählenden mit dem Verfasser des gesamten Textes gleichsetzt - „Ich [...] packte das Erhebliche in eine Mappe, um es nach Wien mitzunehmen" (I, 13) - in der Buchfassung zum ersten Mal in einem Zusammenhang, der, die Lektüreerfahrung des Vaters für überholt erklärend, die ordnungslose väterliche Schreib- und Lesepraxis auf die werkorientierte Autorschaft des Sohnes hin überwindet: „Mein Vater hat den zweiten Band der Mappe gar nicht gekannt. Er war in der alten Truhe und wurde erst von mir gefunden [...].“ (II, 234) Eben dieser zweite Band aber, so suggeriert die Beschreibung der urgroßväterlichen „Lebensmappe“, ermöglicht die Neuschöpfung der ,Mappe' als Mappe, insofern er mit seinen zahlreichen freigebliebenen Seiten die Möglichkeit bereitstellt, sie eigenständig fortzuschreiben: „Allen Anzeichen nach war der Doctor schon achtzig Jahre alt, als er den zweiten Band seiner Lebensmappe machte und vorrichtete, und dennoch machte er diesen Band so dick, wie den ersten [...]."(II, 234)24

Je mehr Material Stifter dann in der erklärten Absicht, ,aus der Mappe des Urgroßvaters ein eigenes Werk in zwei Bänden zu machen," 25 in seinen Text integriert, desto deutlicher läßt die solcherart fortgeschriebene Mappe erkennen, daß die fragmentarische Erscheinungsform ihrer Quellen selbst Instrument auktorialen Gestaltungswillens ist. So erreicht bei der Beschreibung der Papiere, die der Rahmenerzähler in der von ihm erbrochenen Truhe vorfindet, der Nukleus aus der Journalfassung - „ein Wust obscurer Sachen - Packpapier blau und grau, Rechnungen, ein vergelbter Prozeß in Sachen einer Hutweide, meine eigenen abgeschossenen Schönschreibbücher, Recepte" (I, 13) - in der letzten Fassung zwar ein Vielfaches seines einstigen Umfangs, die Heteroge-

An Gustav Heckenast, 22. März 1850 (PRA 18, S. 33). 
nität des Vorgefundenen aber wird durch die überaus sorgfältige diskursive Anordnung konterkariert, mit der der Text hier eine individuell auf den Rahmenerzähler zugeschnittene Kulturgeschichte der Schrift präsentiert. Zunächst finden sich hier „ganz unnüze Blätter“ ohne jeden Eintrag, ,andere, auf denen nur ein paar Worte standen, oder ein Spruch“, schließlich „solche, auf denen mit Nadeln allerlei Zierrath ausgestochen war, meist ein Herz mit einer Flamme darüber" (IV, 15), Grenzfälle sprachlicher Sinngebung und als solche ein Präludium zu einer ersten Pointe: „Dann fand ich meine eigenen Schönschreibbücher, dann einen papierenen Handspiegel, von dem aber gerade das Spiegelglas heraus gebrochen war [...]" (ebd.). Die ,Schönschreibbücher", die zu Beginn der Mappe erfolgte Erwähnung von des Ich-Erzählers ,Schulauszeichnungen" wieder aufnehmend, erinnern an den Ursprung von Schriftkompetenz im fremdbestimmten Kopistentum kindlicher Schulbildung, während der ,Handspiegel' die narzißtische Bedrohtheit des Autors als Erfinder repräsentiert - eine Bedrohtheit, die im Kontext der Mappe einer der Fragmentarizität des Materials diametral entgegengesetzten Sogwirkung zugeschrieben wird, birgt doch die anerzogene Gewohnheit des Kopisten, bekannte Muster zu reproduzieren, die Gefahr, Fremdes wie etwa die Aufzeichnungen Augustinus' anhand scheinbar vertrauter Umrißlinien wie selbstverständlich zum ,papiernen Handspiegel' und damit zum Garanten eines eigenen Selbstentwurfs umzuschaffen.

Im Anschluß folgt eine Aufzählung, in der zwar die von der Journalfassung erwähnten ,Recepte - von Aspetsberger als Kennwort für das zur Anwendung „fertig entwickelte formale Prinzip“26 von Augustinus' und des Obristen Schreibpraxis identifiziert - fehlen, dafür aber die formalisierte Kommunikationspraxis europäischer Schriftkultur in ihrer ganzen Bandbreite eingeholt wird: Zum Vorschein kommen Zeugnisse der Ökonomie - „Rechnungen“ - , der Justiz - „eine sehr vergelbte Verhandlung über eine Hutweide“-, der Gelegenheitspoesie - ,unzählige Blätter mit Liedern, die niemand mehr singt" -, gesellschaftlicher Korrespondenzgewohnheiten - ,eine ungemeine Menge von Briefen mit den seltsamsten Arten, sie zusammen zu legen, sie handelten von Bestellungen Danksagungen Anfragen Wünschen Beileid und dergleichen“und eines rokokohaft stilisierten Liebesdiskurses - ,einige waren auch da mit längst ausgebrannter Liebe, sie waren immer auf schöneres Papier geschrieben und hatten oft am Rande und oben gemalte Verzierungen, auf einigen standen Schäfer und Schäferinen" -, und schließlich auch Ordnungsinstrumente dieser Kultur, ihrer einstigen Funktion längst verlustig gegangen: „[...] dann waren sehr viele Fächer und Büchschen da theils aus Pappe theils aus Holz selbst aus Porzellan, dann Schnitte für Kleider, die jetzt niemand mehr trägt, Rollen Pakpapieres, in das nichts mehr gewikelt wird, auch unsere Kinderschulbücher waren da aufbewahrt" [...]" (ebd.). Noch vor den Schriften des Vaters schult hier die Sichtung des Truheninhalts den Rahmenerzähler für die Lektüre von 
Augustinus’ Aufzeichnungen als „ein Buch, das kein Kinderbuch war“ (IV, 16) und als solches die Wahrnehmungsgewohnheiten des Kopisten irritieren muß, enthält es doch „das Leben des Doctors [...] nicht gerade so Schritt für Schritt [...] sondern Abtheilungen, die ihm merkwürdig geschienen haben mochten. Auch Betrachtungen Ansichten Naturereignisse waren eingetragen [...]" (IV, 25f.). Im Unterschied zu den frühen Fassungen vermeidet der Rahmenerzähler hier Reflexionen über die Präsentationsform des Gelesenen und rückt dann am Ende des ersten Kapitels auch nicht den folgenden Text in den Blick, sondern vielmehr den Rahmen, in dem die überlieferten Fragmente ihren Sinn nur entbergen können, ,unser Vaterhaus das Haus unserer Erinnerungen“" (IV, 28).

Mit diesen Worten öffnet die letzte Fassung des ersten Kapitels die Struktur der Rahmenerzählung im Moment ihrer Vollendung wieder auf eine übergreifende Verschränkung zwischen Rahmen- und Binnenerzählungen hin. Im Kontext der ersteren vollzieht sich die Schließung als Wiederaufnahme des Eingangszitats, das Lektüre als produktiven Besuch in den ,Wohnungen der Vorfahren' codiert hatte. Die Analogisierung von Literatur und Architektur, die in den früheren Fassungen eher beiläufig geblieben war, macht die von deren Rahmenerzählern als geradezu zwanghaft geschilderte Übernahme des Fragmentarischen als bewußt gewähltes Bauprinzip kenntlich, das, zur Herstellung ästhetischer Kohärenz über die Grenzen der einzelnen Fragmente hinaus eingesetzt, bereits den Selbstentwurf des Autors als Stifter umspielt: Das ,Vaterhaus' ebenso wie die Binnenerzählungen sind von Augustinus begründet worden, erst der Rahmenerzähler aber garantiert mit dem Erhalt des ,Vaterhauses auch den Überlieferungsraum, in dem der Stifter historisch als solcher identifizierbar wird - durch eine Inszenierung seiner Niederschrift als einer Stiftungsurkunde, die, so deutet das Bild vom herausgebrochenen Spiegelglas an, ihrerseits die Voraussetzung zu Identifikation des Rahmenerzählers bereitstellen soll, den artifiziellen Charakter dieser Inszenierung aber durchweg in den Bruchstellen zwischen Augustinus' Erzählungen und solcherart die Rekonstruktion als eine vom Rahmenerzähler betriebene Konstruktion bewußt hält.

\section{III}

Die Binnenerzählungen lösen den Zusammenhang zwischen dem schriftlichen Gründungsakt und seiner erzählerischen Inszenierung ein, indem sie die Beziehung der von Augustinus verfaßten Bände zum Projekt der Mappe in der Beziehung zwischen dem ersten Text des ersten Bandes und der anschließenden Durchführung von Augustinus' Schreibprojekt handlungschronologisch vor- und textchronologisch nachgestalten. In der Journalfassung weist der Rahmenerzähler der Erzählung vom „sanftmüthigen Obristen“ zu Beginn des zweiten Kapitels die programmatische Funktion des Ausgangstextes zu: „Der Aufsatz ist der erste, der im Lederbuche im ersten Tomus steht, und die Begebenheit, die darin erzählt wird, scheint sogar die Veranlassung zu dem ganzen 
Lederbuche gegeben zu haben“ $(I, 14)$. Diese ,Begebenheit" ist die Geschichte einer Leidenschaft, die von ihrem selbstzerstörerischen Potential im letzten Moment zur Sprache erlöst wird. Es ist „ein unbeschreiblicher Augenblick“ (I, 15), in dem der junge Augustinus sich aus unglücklicher Liebe zur Tochter des Obristen an einer Birke zu erhängen plant, während „seltsame Stimmen in dem grabesstillen Walde“ (I, 16) die Grenzen menschlichen Ausdrucks umspielen und der Augenblick, in dem Augustin durch den Obristen in die disziplinierenden Ordnungen solchen Ausdrucks zurückgeholt wird: Auf seine Berührung hin fällt Augustin spontan in die Gewohnheiten verbaler Kommunikation durch sinnvolle Fügung von Wortgruppen zurück und ist ,eines Satzes an der Gegenseite der Birke“ (I, 16 Hervorhebung U. L.).

Statt einer Diagnose des Sprachverlustes aber, mit dem der Identität des Liebenden ihre Auslöschung droht, legt der Autor der Mappe dem Obristen einen Hinweis auf die Sprachmacht des Dichters in den Mund: "Ihr müßt in tiefe Studien versunken seyn, daß Euch der Gruß eines Freundes so erschrekken konnte“" $(I, 16)$. „Studien,““, ruft Augustinus daraufhin „mit schwebender Stimme“ aus, „Studien - wie meint Ihr das?“" (ebd.). Innerhalb des Textes durch des Obristen Annahme, Augustinus habe wohl „heroben lesen“ (I, 17) wollen, beantwortet, zielt diese Frage gleichwohl aus dem Text heraus auf das Wissen seines Lesers um die Zugehörigkeit der Mappe zum Komplex der Studien. Damit fungiert die Schilderung des Selbstmordversuchs nicht nur im Sinne des Damaskuserlebnisses, das zur traditionellen Rhetorik der Stiftungshistoriographie gehört, als Stiftungsurkunde für die von hier ausgehende Niederschrift der Binnenerzählungen, sondern sie überträgt durch die Einbettung des Textes in den Entstehungs- und Publikationskontext einer Folge erzählerischer Fiktionen zugleich das Paradigma der heilenden Niederschrift auch auf den Akt, mit dem der Autor der Studien in der Mappe die Disziplinierung poetischer Leidenschaft auf die von ihm angestrebte Klassizität seiner Dichtung hin betreibt.

Schon in der Buchfassung ersetzt Stifter die Passage, in der der Rahmenerzähler der Journalfassung die Geschichte vom ,sanftmüthigen Obristen“ als Gründungserzählung der Aufzeichnungen einführt, durch einen Text, der, unter dem Titel „Das Gelöbniß“ als eigenes Kapitel abgegrenzt, die implizite durch eine explizit gegebene Stiftungsurkunde ablöst: „Vor Gott und meiner Seele“ verspricht der Schreibende ,hier einsam und allein, daß ich nicht falsch sein will in diesen Schriften, und Dinge machen, die nicht sind, sondern, daß ich es lauter schöpfe, wie es gewesen ist, oder wie es mir mein Sinn, wenn er irrig war, gezeigt hat" (II, 31). Indem sich der Binnenerzähler hier doppelt gegen die poetische Kontaminierung historischer Wahrheit abgrenzt, beschwört er zugleich die Relativität seiner Wahrheitsformel, verweist doch die Beteuerung, daß er ,lauter schöpfe‘, auf das schöpferische Schreiben, während die Berufung auf einen gegebenenfalls, irrigen Sinn' der jeder sprachlichen Formung vorhergehenden sinnlichen Aufnahme des Geschilderten ihre Störanfälligkeit bereits einschreibt. Die disziplinarische Komponente seiner Aufzeichnungen 
dagegen konkretisiert sich erst in dem streng ritualisierten Rhythmus von Niederschrift, Versiegelung und Relektüre, mit dessen Setzung Augustinus seiner Schreibpraxis das Gepräge eines religiösen Kultes verleiht. ${ }^{27}$ Gleichzeitig führt die Formulierung, mit der der Erzähler die Geschichte seines Selbstmordversuchs für das folgende Kapitel ankündigt, jenes Heilsstreben in die Textproduktion ein, das die Briefe Stifters während seiner Arbeit an der Buchfassung so nachdrücklich mit der Vollendung der Mappe verknüpfen: „Es ist eine fast traurige und sündhafte Begebenheit, die mir das Gelöbniß und Pergamentbuch eingegeben hat: aber die traurige Begebenheit wird in Heil ausgehen, wie schon das Pergamentbuch der Anfang des Heiles sein muß“ (II, 31f.).

In der letzten Fassung schließlich erweitert Stifter das Programm des Gelöbnisses um eine Passage, die „[a]uf der ersten Seite der ersten Bandes“ das Buch in der Rolle eines Stiftungswerkes und in dieser Rolle zugleich als Gegenstand des von dem Werk dokumentierten Venerationskults präsentiert:

Sei gegrüßt, mein Buch. Kollmann in Prag hat dich recht gemacht, du bist schön und fest für die ernste Sache. Sei gegrüßt, und sei der Ekstein meiner Zukunft. Weil es seit einem Monate gewiß ist, da $\beta$ ich mir kein Weib antrauen werde, und da $\beta$ ich keine Kinder haben werde, so sei du mein Weib und mein Kind, und irgend ein fremder Mensch wird dich nach meinem Tode ehren (IV, 29).

Als buchbinderisches Artefakt in Auftrag gegeben, wird das Buch als Trägermedium in den Dienst jener, ernsten Sache" gestellt, durch die der Schreibende die Funktion des Auftraggebers in der des Ausführenden aufgehen läßt, der Niederschrift, mit deren Beginn Augustinus den ,Ekstein“ einer von zerstörerischen Leidenschaften geheilten Zukunft zu legen hofft. In unmittelbarem Anschluß daran gibt die Apostrophe des Augustinus wie in den vorigen Fassungen auch den Blick auf die Fiktionalität dieses ,Eksteins` frei, ist doch der nun folgende Teil des Gelöbnisses bereits a priori von der Rahmenerzählung entkräftet worden - statt in mönchischer Einsamkeit auf sein Buch fixiert zu bleiben, wird Augustinus, wie der Leser zu diesem Zeitpunkt bereits weiß, mit Margarita am Ende eben doch in dem von ihm erbauten Haus den Familienzweig gründen, aus dem stammend der Rahmenerzähler ihn später als Stifter identifizieren wird. Auf der Handlungsebene kompensiert das Buch demnach gerade nicht die genealogische durch die schriftliche Selbstverwirklichung, sondern erfüllt seinen Auftrag darin, dem ersteren durch das zweite den Weg zu bereiten, so daß die Mitteilung der Binnenerzählungen folgerichtig mit der Vereinigung der Liebenden schließt. Auf der poetologischen Ebene dagegen deutet die architektonische Metapher des ,Eksteins“ auf Stifters Anspruch, mit der Vollendung der Mappe das Gefüge der Literaturgeschichte, wie es vom Eingangszitat der Mappe über die ,Wohnungen der Vorfahren' in den Bedeu-

27 Vgl. auch den Begriff des „Vertragswerks" bei Aspetsberger (wie Anm. 19), S. 12; auf die Bedeutung von Ritualen in Stifters Werk und deren religiöse Dimension weist bereits Rudolf Wildbolz hin: Adalbert Stifter: Langeweile und Faszination. Stuttgart u. a. 1976, S. $114 \mathrm{ff}$. 
tungshorizont des, Vaterhauses‘ eingespeist worden ist, um einen eigenen Bau zu erweitern - in Gestalt eines Textes, den er Heckenast gegenüber im Juli 1847 selbst als solchen Bau beschreibt, befürchtete er doch, daß, wenn er an der Mappe noch „einen Stein rühre, gleich ihrer eine Menge nachrollen, und dann aus einem Trümmerwerke heraus zu bauen ist" .28

In Augustinus' Niederschrift wird die Spannung zwischen ritualisiertem Schreiben und poetischer Schöpfung von den beiden einander als Gegensatzpaar zugeordneten Figuren des Obristen und Eustachius' repräsentiert. Dabei verweisen die Anfänge der Geschichte des Obristen besonders in der Journalfassung auf diese und damit auf die Anfänge Stifters als Autor selbst zurück, auf das im Juni 1841 beginnende periodische Erscheinen der Mappe in der Wiener Zeitschrift fur Kunst, Literatur, Theater und Mode - nicht zufällig werden die Karten, an denen der Obrist die Lust am Glücksspiel erfährt, in dieser Fassung im Unterschied zu den späteren noch als „bunte Blätter“ (I, 23) beschrieben, mit einem Begriff also, der über die Spielkarten hinaus auch auf das Zeitungs- und Zeitschriftenwesen hin lesbar ist, in dem der junge Autor in diesen Jahren erstmals durch seine Arbeiten Geld verdient. In der Erzählung des Obristen allerdings erscheint solcher Gelderwerb als Resultat einer Mischung aus Leichtsinn und Unwissenheit, greift doch der junge, eben in Paris angelangte Adelige ,nach einem der Blätter, die auf dem Tische lagen, wie ich es die Umstehenden thun sah, und legte mein Goldstück darauf, ohne das geringste von dem Spiele zu verstehen“, einzig getrieben von materieller „Lüsternheit" (I, 23).

Die korrumpierende Macht des Geldes, die von derart spielerisch er̨zielten Gewinnen ausgeht, wird in der Geschichte des Obristen durch den Akt konterkariert, mit dem er sich dieser Gewinne gegen ,lauter Empfangsbriefe über verschiedene Summen und Stücke, welche der Graf Casimir Uhldom, Spieles wegen, der Armensache übergeben hatte, und welche durch die Namen der Väter bestätiget wurden, in deren Hände das Gut niedergelegt worden war" (II, 47), zugunsten einer karitativen Stiftung entledigt, die schließlich in den letzten Fassungen, beiläufig auch auf den genealogischen Aspekt des Stiftens anspielend, konkret „Waisenkindern" (IV, 203) zugute kommt. Erst nach einem Selbstmordversuch aus Liebeskummer aber lernt der Obrist jenes „Mittel gebrauchen, von dem ich glaube, daß ich ihm Alles verdanke, was ich geworden bin" - ein Mittel, dessen identitätsstiftende Macht sich am Obristen in dem Moment vollendet, in dem er, Augustinus seine Lebensgeschichte erzählend, nun auch zum Mentor von dessen schriftlicher Identifikationsstiftung wird:

Ein alter Kriegsmann rieth es [...] in meiner Gegenwart einer Jungfrau an, die in Liebesgram war, und sterben wollte. Es besteht darin, daß man alle seine Gedanken und Begebnisse, wie sie eben in der Zeit sind, aufschreibt; dann aber einen Umschlag darum siegelt, und das Gelöbniß macht, die Schrift erst in drei oder vier Jahren aufzubrechen und zu lesen. Da sei Alles anders, und man lerne erst, wie man gewesen. (IV, 206) 
Die Erkenntnis, ,wie man gewesen', soll über die kritische Relektüre des einst Geschriebenen zur Einebnung der Unterschiede zwischen den einzelnen Schreibphasen hinführen. „Ich schrieb sehr fleißig an meinen Päken“, rekapituliert der Obrist in der letzten Fassung, „sie wurden immer gleichartiger, bis jetzt die, welche ich in meinem Alter öffne, einer wie der andere sind" (IV, 221). Die Differenzen, die von diesem Nivellierungsproze $\beta$ betroffen sind, entstehen dabei nicht so sehr am zwangsläufig je unterschiedlichen historischen Stoff der einzelnen ,Päke' als vielmehr in dessen Darstellungsmodi, deren Unterschiedlichkeit die Stadien auktorialer Stilbildung sowohl auf der sprachlichen als auch auf der Ebene von Anordnung und Bewertung des Geschilderten dokumentiert. Der Geschichte des Obristen zufolge gelangt der Autor in dem von Stifter angestrebten ,klassischen' Sinn demnach durch die Erziehung seiner selbst zu einer Ausdruckskonvention, die die Vielfalt der verarbeiteten Stoffe frei von jedem erratischen Überschwang auf immer gleiche Weise präsentiert, so daß die entstehenden Texte schließlich keiner Überarbeitung mehr bedürfen - eine derart geglückte Erziehung aber macht den Autor nicht nur zum Kopisten eines von einem anderen - dem anonymen ,Kriegsmann" - verantworteten Rezepts, sondern letztlich geradezu zum Kopisten seiner selbst.

Diesem Modell gegenüber verkörpert Eustachius das des Autors als Erfinder $^{29}$ in umsó reinerer Form, als sein erstes Auftreten in dieser Rolle zunächst eine der Geschichte des Obristen sehr ähnliche Ausgangsposition markiert, wenngleich hier die Anspielung auf den Publikationskontext der Mappe ungleich deutlicher lanciert wird: Er habe „die Wochen her auf viele Blätter Papier Hirngespinnste geschrieben“, erklärt er dem neugierigen Augustinus seine plötzliche Solvenz, ,[...] bis mir auf einmal die Verwegenheit kam, daß ich auf die Schreibstube der lustigen und ernsten Stadtchronik rannte und Alles vorzeigte. Da haben sie es nun gedruckt, einen wildfremden Namen vorangesetzt, und mir fast eine halbe Handvoll Goldstücke gegeben“ (I, 47). Die von der Journalfassung dazu entworfene romantisierende Schreibszenerie - „da ging ich des Nachts in der Stube herum, und redete mit mir selbst, und da kam es über mich, als wär' ich Einziger eine versammelte Menge, die braust und rathschlagt - und dann war es mir wunderselig und hold, wenn ich hin und her rannte, und schrieb und schluchzte - -“ (I, 49f.) - wird von der letzten Fassung zwar entschieden verknappt, dabei aber erst recht auf den Kontrast zum Schreiben des Obristen zugespitzt: Nachts, so berichtet Eustachius, „schrieb ich in meiner Stube Manches auf, das mir in mein Herz gekommen war. Ich schrieb recht vieles auf. Und wenn ich noch so allerlei Anderes hatte thun müssen, so waren diese Dinge jetzt mein Eigenthum, und ich schrieb wieder

29 Zur Bedeutung der Künstlerfigur in Stifters Werk vgl. Sibylle Appuhn-Radtke: „Priester des Schönen'. Adalbert Stifters Künstlerbild zwischen theoretischem Anspruch, literarischer Darstellung und gesellschaftlicher Realität". In: Laufhütte/Möseneder (wie Anm. 5), S. 75-95. 
neue hinzu“ (IV, 45) - Eustachius' Schreibvermögen ist nicht das Produkt mühsam erworbener Affektkontrolle, sondern es entsteht, darin der Geniekonzeption des 18. Jahrhunderts verwandt, im Gegenteil spontan aus einem selbst affekthaften Drang nach Ausdruck.

Für die Aura der genuinen Schöpfung aber, die Eustachius' Schreibpraxis gegenüber derjenigen des Obristen auszeichnet, erlegt der Poet einen hohen Preis. Während nämlich die radikale Selbstbezüglichkeit der vom Obristen verfaßten Texte diesen von vornherein die Autonomie klassischer Ästhetik einschreibt, verfällt die Figur des kreativen Autors ab dem Zeitpunkt, ab dem er zur Stabilisierung seiner Identität auf die gewinnbringende Liquidierung seines ,Eigenthums' angewiesen ist, einem katastrophalen Autonomieverlust. Als er des verfallenden Schuldscheins eines Kommilitonen wegen, auf den er „seinen Namen gesetzt hat" (IV, 49), dazu gezwungen ist, angesichts drohender Pfändung über Nacht aus der Stadt zu verschwinden, und mit seinem guten Ruf zugleich auch die Option darauf verliert, durch Beendigung seines Jurastudiums einen bürgerlichen Beruf zu ergreifen, bleibt ihm zur Wiederherstellung seiner gesellschaftlichen Integrität einzig die Möglichkeit, sein Dichtertum zu professionalisieren. Zur Vermarktung seiner Schriften allerdings bedarf er der Hilfe Augustinus', den er in seinem Abschiedsbrief zu deren Sachwalter bestimmt: „Ich übergebe dir alle meine Schriften. Lese sie, du darfst Alles lesen. Zwei Päke, auf denen 1 und 2 steht, lasse druken, das wird alles bezahlen; aber die andern nimm zu dir in deine Wohnung" (IV, 49f.). Augustinus aber unterläßt die erbetene Publikation und nimmt die mit eigenem Geld ausgelösten Schriften mit sich in sein Heimatdorf, um sie dort jedem Zugriff der Öffentlichkeit zu entziehen: „[...] nie hat ein Mensch bis auf den heutigen Tag von Augustinus erfahren können, was denn in den vielen Heften des Eustach stehe“" (I, 66).

Während die Journalfassung nur andeutet, daß Augustinus damit selbst für das von ihm beklagte Ausbleiben Eustachius' verantwortlich ist, und die Buchfassung dessen Geschichte ganz ausspart, rücken die beiden letzten Fassungen den darin skizzierten Konflikt in das Zentrum des Textes. Den Vorwürfen, mit denen Eustachius' Zimmerwirtin Cäcilie Augustinus' wiederholten Anfragen um Nachrichten von dem Vermißten begegnet - „Ihr hättet ihn suchen sollen und dann Arzt werden," sagte sie" (IV, 91) -, vermag Augustinus, am Vorbild des Obristen inzwischen zur Niederschrift verbindlicher Auskünfte über den eigenen Entwicklungsgang geschult, noch mit dem Argument zu begegnen, man müsse ,[b]ei jedem Suchen [...] ein Merkmal finden, das den Weg des Suchens angibt. Ich habe alle seine Schriften gelesen, und es ist in ihnen kein Merkmal“ (IV, 92). Eustachius' Geliebte Christine aber zitiert erst Eustachius' Brief an Augustinus - „ich werde kommen, wenn ich es mit der Ehre kann“ (IV, 110) -, um Augustinus dann ausdrücklich schuldig zu sprechen: „Ihnen hat er geschriebene Worte hinterlassen, deren einige lauteten, daß sie Papiere, die er bezeichnet hat, druken lassen sollten, damit daraus die Zahlung erfolge. Sie hätten auf diese Zeilen des Briefes als auf eine Weisung zeigen können, in 
der die Dekung enthalten ist" (IV, 110f.), resümiert sie; Augustinus aber habe dies unterlassen und damit die Wiederherstellung von Eustachius' ,Ehre‘ sabotiert.

Hier skizziert die Mappe eine kausale Beziehung zwischen Veröffentlichung und auktorialer Identität, die Stifter schon vor der Publikation seiner ersten Erzählung Der Condor im Jahr 1840 thematisiert. In einem Brief an Sigmund von Handel vom 8. Februar 1837 etwa erteilt er diesem bezüglich seiner einstigen schriftlichen Hinterlassenschaften - zu diesem Zeitpunkt noch der von ihm geschriebenen Briefe - einen Auftrag, der denjenigen Eustachius' an Augustinus fast zu präfigurieren scheint: ,[...] ich beschwöre meine Freunde, bei denen die Kapitel ad mea opera omnia herum liegen, [...] nach meinem Tode Alles herauszugeben. Sonst fahre ich ab und bin kein Schriftsteller gewesen."30 Besonders aber in einem Brief an Gustav Heckenast vom 2. August 1841 äußerte Stifter seine Verstimmung wegen des von ihm befürchteten Nichterscheinens von der Erzählung Der Hochwald in Heckenasts Iris für das folgende Jahr mit einer Vehemenz, die ein bezeichnendes Licht auf Eustachius' Verschwinden wirft: ,[...] alle Welt weiß es hier, und nun erscheint sie nicht, ich bin compromittiert, und bin im Erscheinen meines Nahmens unterbrochen [...]. Der Gedanke ist mir so unleidlich, daß er mich verfolgt, und für alle Arbeit untüchtig macht [...]."31 Mag der Dichter selbst noch so beschwörend sein ,Eigenthum' in die Wertschöpfungsmechanismen der bürgerlichen Gesellschaft einschreiben - erst das ,Erscheinen" von des Autors ,Nahmen', die Veröffentlichung eines von ihm verfaßten Textes, kann dieses ,Eigenthum ${ }^{6}$ als Besitz legitimieren; unterbleibt es, veschwindet der solcherart ,compromittierte" Autor nicht nur aus den Augen des lesenden Publikums, sondern wird selbst zu jeder weiteren literarischen Produktion, untüchtig؛.

Vor diesem Hintergrund gewinnt die suspendierte Beziehung Augustinus' zu Eustachius das Gewicht einer komplementär zu derjenigen zu Margarita angelegten Erzählachse. Die poetologische Bedeutung des verschwundenen Autors wird dabei durch einen Kunstgriff markiert, der in den frühen Fassungen durchweg auf den Rahmenerzähler angewandt worden war, durch die Verknüpfung der Figur des Eustachius mit dem Begriff der Mappe. Schon bei Augustinus' Gespräch mit dem Prager Bürgermeister wird dieser Begriff mit der Suche nach ihm in Verbindung gebracht: Als Augustinus dem Bürgermeister seinen „Aufenthaltsort auf ein Papier geschrieben“ überreicht, legt dieser „das Papier in eine Mappe“ (IV, 98). Tatsächlich stößt Augustinus dann in einer Mappe auf die Spur des Freundes, einer Mappe allerdings, die sich vom bürokratischen Ordnungswerk der Stadtverwaltung ebenso kategorisch unterscheidet wie von den psychographischen Ortsbestimmungen Augustinus' und des Obristen. Dieser Differenz entsprechend kann Augustinus diese Spur zunächst nicht lesen, findet sie sich doch in einem von Eustachius entworfenen 
Garten, in dem nicht nur Schönheit und Nützlichkeit organisch miteinander verbunden, sondern auch die Reste eines ehemaligen Schlosses Teil der Gesamtanlage sind.

Vor allem diese Ruine verweist einmal mehr auf die selbstreferentielle Dimension des Textes, scheint doch ihre Funktion für das „Kunstwerk“ des Gartens, dessen Wirkung Augustinus seinem Besitzer gegenüber „wie von einem Buche“ (IV, 277f.) ausgehend beschreibt, Stifters 1847 erfolgte Prophezeihung einzulösen, er werde bei einer neuerlichen Überarbeitung der Mappe „aus einem Trümmerwerke heraus [...] bauen“" ${ }^{2}$ müssen: Durch „allerlei Getrümmer" der ehemaligen Schloßbauten steigt Augustinus auf einen Hügel, auf dem er sich an der vor ihm liegenden Landschaft „nicht sattsehen kann“, und erst oben erkennt er „deutlich, daß der Schutt zu einer Treppe und zu einer Ausschau hergerichtet worden sei, obgleich Alles den Anschein hatte, als sei es immer so gewesen“ (IV, 275) - im Rückblick auf die Metapher des ,Eksteins“ gelesen, spricht der Text hier von sich als einem Werk, das erst durch die Integration der früheren Fassungen eine ,Ausschau' auf die ganze Schönheit seine Vollendung erlaubt, und deutet zugleich auf Stifters Verwandtschaft mit Eustachius, hat letzterer doch mit seiner Umgestaltung des Gartens idealtypisch jene „Kulturationsarbeit" geleistet, die Stifterș Werk durchweg als Auftrag des Künstlers profiliert. 33

Auch die Auskünfte des Fürsten zur Entstehungsgeschichte des Parks machen den Text der Mappe auf die Arbeit des Poeten durchlässig, verwendet der Fürst doch darin das Wort ,Mappe' gleich viermal: Ein Freund, so berichtet er, habe von der Hand des Zeichners "sehr zierliche Mappen von Landschaften, wie man Mappen von Ländern hat", gesehen, und auf seine Bitte hin habe der Künstler zugesagt, ,er wolle ihm die Zeichnungen noch einmal und dazu viel ausgedehntere Mappen machen. So ward es beschlossen, und in nicht langer Zeit waren die Zeichnungen und die Mappen fertig“ (IV, 279f.). ,Mappe“ allerdings heißt im Sprachgebrauch des Fürsten hier ausschließlich ,Landkarte', so daß das Spiel mit den beiden Bedeutungen des Wortes nunmehr auch jene Differenz zwischen Schöpfer und ordnendem Sammler in den Text einzieht, die gerade nicht Eustachius, sondern Augustinus als poetologische Schlüsselfigur der Mappe etabliert, führt doch erst Augustinus in der Schilderung des Besuchs, bei dem er die Karten zu sehen bekommt, die Bedeutung des Ordnungsinstruments ein, der der Text seinen Namen verdankt: Der Fürst „öffnete

Ebd., S. 239.

33 Christian Begemann: „Natur und Kultur. Überlegungen zu einem durchkreuzten Gegensatz im Werk Adalbert Stifters“. In: Adalbert Stifters schrecklich schöne Welt. Beiträge des internationalen Kolloquiums zur A. Stifter-Ausstellung (Universität Antwerpen 1993). Hrsg. von Roland Duhamel, Johann Lachinger, Clemens Ruthner und Petra Göllner. (Jahrbuch des Adalbert-Stifter-Institutes Linz 1/1994), S. 41-52, hier S. 42; sowie in größerem Zusammenhang zu diesem Garten und seiner poetologischen Funktion ders.: Die Welt der Zeichen. Stifter-Lektüren. Stuttgart/Weimar 1995, S. 353-358. 
die Mappe selber, und legte mir Blat für Blat nach der Ordnung vor. Es waren ziemlich viele Blätter, die meisten davon waren Mappen" (IV, 303).

Am Begriff der Mappe erfährt Augustinus' bisher scheinbar so fahrlässiger Umgang mit den Schriften des Freundes seine Rechtfertigung. Das Verfahren nämlich, mit dem er in den späten Fassungen der Mappe um die Integration einzelner Geschichten zu einem tradierbaren Ganzen ringt, bildet das genaue strukturelle Pendant zur medizinischen Praxis des Arztes und ist als solches einem Ethos verpflichtet, das jede Hilfe zur Selbstzerstörung kategorisch ausschließt. Eustachius' Geschichte aber ist die einer Selbstzerstörung durch Kunst, hatte er doch schon in seinem Abschiedsbrief das Fragmentarische seiner Schriften als eigentliches Residuum seiner Identität lanciert - ,[...] liebe sie; denn jedes kleine Stückchen ist dein Eustach" (I, 57) - und schließlich, insofern er nur einen Teil seiner Werke zur Publikation bestimmt hatte, die Wiederherstellung seiner Ehre an eine neuerliche Fragmentarisierung gekoppelt. So ist Eustachius' Umgang mit Schrift von Anfang an Augustinus' Veranlagung zum Jähzorn verwandt, die den stets ,an der Seite einen scharfen Schläger" oder doch zumindest „einen Stok“ (IV, 31) tragenden Medizinstudenten Augustinus jederzeit bereit sein läßt, Gewalt anzuwenden, sei es im Duell, sei es in einer Prügelei, immer aber mit dem Risiko, dem hippokratischen Eid entgegen anderen Menschen Verletzungen zuzufügen. Eustachius trägt „beschriebene Papiere“ (ebd.) in der Hand; als das Instrument, mit dem Eustachius sich in ,Stückchen' zerlegt, sind diese nicht weniger Waffe als der Degen Augustinus' und werden von ihm zudem Christina gegenüber in ähnlicher Weise wie der "Schläger an der Seite" (IV, 36) durch Augustinus als Signal erotischen Werbungsverhaltens eingesetzt, betört er doch die Geliebte vor allem durch den „holde[n] Duft“ seiner „Dichtungen“. (IV, 332) Anders aber als Augustinus, der sich in seiner Heimat bezeichnenderweise mit der Heilung des Bettlers Tobias von einem lebensgefährlichen Leiden am „Unterleib“ (IV, 78) als Arzt etabliert, ${ }^{34}$ unterläßt Eustachius später neben der Bändigung seines schriftlichen Drangs zur Selbstauslöschung auch diejenige seiner erotischen Wirkung - mit der Konsequenz, daß die Tochter des Fürsten, dessen Garten er umgestaltet hat, der ,eigenthümliche[n]“" (IV, 332) Ausstrahlung des Künstlers mit einer Leidenschaft verfällt, deren pathologische Züge erst von Augustinus wieder korrigiert werden können.

Augustinus' Buch stellt die für seine Entwicklung entscheidende Gelenkstelle zwischen Schrift und Körper durch das Material bereit, aus dem es auf seinen eigenen Auftrag hin gemacht ist: ,[...] o Buch des Pergamentes“ (I, 71), apostrophiert die Journalfassung; „Das Buch bestand aus Pergament“ (II, 24),

Vgl. zu dieser Episode auch Hubert Lengauer: „Konstitution und Selbstbeherrschung. Zum Verhältnis von Lebensgeschichte und Zeitgeschichte und Stifters ,Mappe ““. In: Johann Lachinger, Alexander Stillmark und Martin Swales (Hrsg.): Adalbert Stifter heute. Londoner Symposium 1983. Linz 1985 (Schriftenreihe des Adalbert-Stifter-Institutes des Landes Oberösterreich 35), S. 135-151, hier S. 147f. 
vermerkt die Buchfassung; "Die Blätter waren lauter Pergament" (IV, 16), heißt es in der dritten wie in der letzten Fassung; alle vier betonen dieses Material durchweg mit der Redundanz eines überstrapazierten Leitmotivs, und die beiden letzten fuihren schließlich auch die Approbationsurkunde des Augustinus als „Doctorpergament" (IV, 51) ein und erweitern die Beziehung zwischen Heilen und Schreiben zudem auf das Bildfeld der Architektur hin, wird doch in den Grundstein für das Haus des Obristen unter anderem ,ein feines Pergament“ eingemauert, ,auf welchem die Nachricht des Baues geschrieben war". (IV, 153) Dergestalt sowohl an den Gründungsakt von Augustinus' Heilpraxis als auch direkt an die Funktion einer Stiftungsurkunde angeschlossen, versinnbildlicht das Pergament als durch kunstvolle Gerbung haltbar gemachte Säugetierhaut jene Domestizierung animalischer Leidenschaft, auf deren Basis Augustinus' autobiographische Aufzeichnungen über ihren individualgeschichtlichen Inhalt hinaus ,Nachricht des Baues“ vom Text der Mappe geben: Von dem Moment an, in dem Margarita auf Augustinus' Eifersucht mit einer grundsätzlichen Abwehr der darin sich entladenden "Erregung“ (IV, 190) reagiert hat, unterlegt der Text Augustinus' schriftlicher Arbeit an seiner restitutio ad integrum $^{35}$ eine Folie aus Krankengeschichten, an denen der Arzt die Heilung verletzter Haut praktiziert.

In der Nacht nach dem Gespräch, in dem der Obrist ihm das Heilmittel des Schreibens angeraten hat, wird Augustinus zu einem Patienten gerufen, dem von einer stürzenden Tanne ,die Haut von dem Fuße gestreift worden" war, und der Arzt sieht sich mit dem erschreckenden Anblick ihrer schützenden Hülle beraubter Kreatürlichkeit konfrontiert: ,[...] nie habe ich so gräßlich menschliches lebendes Fleisch entblößt gesehen" (IV, 228). Analog dazu setzt die Selbstheilung Augustinus' ebenfalls mit einer Entblößung ein, mit dem schonungslosen Rückblick auf ein Leben, das sowohl beruflich als auch gesellschaftlich von den Gewohnheiten reinen Kopistentums geprägt ist - „In der Arzneischule habe ich in zusammengenähte Papiere die Worte geschrieben, die uns der Lehrer gesagt hat [...]. Ich [...] habe in Häusern den Freunden und Mädchen Dinge vorgesagt, die mir auf die Zunge gekommen waren“" (IV, 239) - und damit den Auftrag einer schöpferischen Fortbildung überlieferten Kulturguts verfehlt hat: „Haben nicht uralte Völker ihre Dichtungen auf uns vererbt, sind nicht immer Völker gekommen, die diesen Schaz vermehrt haben? [...] Was habe ich hierin getan?" (IV, 240)

Die Ankunft des ,rothe[n] Buch[s]“" (IV, 246) verspricht die Heilung des solcherart bloßgelegten ,lebendigen Fleischs ${ }^{*}$ - durch eine Kur, die auch und gerade der Geschichte des verschollenen Eustachius gewidmet ist. Auch diese wird von einem Motiv dominiert, in dem Schrift und Haut miteinander verknüpft sind: Der „Koffer“, in dem Eustachius seine Papiere aufbewahrt, ist „mit einer Dachshaut überzogen“ (IV, 45) und gleicht damit vordergründig dem in Leder eingebundenen Buch Augustinus'; als „die Truhe mit der Wild- 
haut" (IV, 113) aber ist er gerade kein Ordnungsinstrument, sondern auf der Ebene der Binnenerzählungen das Pendant zu der Truhe, aus der der Rahmenerzähler das Buch erst hervorholen muß. Der ungeordnete Inhalt findet seine Entsprechung in der ,rissige[n] Haut“ des Koffers, die mit der Identität seines ehemaligen Besitzers - „Es war der Koffer des Eustachius. Gerade an einigen Rissen der Haut [...] war er am kennbarsten" (IV, 113) - auch deren Zerfall dokumentiert - dieser Zerfall aber bedroht so lange, wie Augustinus ihm nicht entgegenzuwirken vermag, auch ihn selbst, kann er doch diese „heilloseste Geschichte [...] wie einen bösen Schaden nicht von mir bringe[n]" (IV, 86). Erst Augustinus' Pergamentbuch erlaubt ihm, die Risse zwischen den Fragmenten von Eustachius' Geschichte so weit zu schließen, daß sie in derjenigen Augustinus' aufgeht, und so den ,bösen Schaden' zu korrigieren, den Eustachius' genialisches Schöpfertum angerichtet hat: „Du aber“, hält Augustinus sich bei Erhalt des Buchs vor, „hättest es vermeiden können, oder kannst es ändern, und die Änderung wird Dir vergolten; denn es entsteht nun das Außerordentliche daraus" (IV, 249).

Parallel zu den ,Änderungen‘, die Augustinus durch das Auffinden von Eustachius' Spur und die wachsende Gewißheit seiner Identität mit dem Zeichner Ewald Lind in die gemeinsame Geschichte einschreibt, schlagen dann drei spektakuläre Heilerfolge auf der Handlungsebene den vom Pergament des Buchs angelegten Bogen von der Haut zur Sprache. Zunächst beweist Augustinus am Fall eines Jünglings, dessen ursprünglich kleine Wunde durch „Pechpflaster“ und „wohlriechende Salben“ (IV, 305) zu einem lebensgefährlichen "Schaden" geworden war, daß er seinen Zugriff auf menschliche Haut durch und durch zu kontrollieren in der Lage ist, entfernt er doch in einer großen Operation erst „mit dem scharfen Messer die Afterbildungen“ und schneidet dann ,immer weiter und weiter [...], daß es mich fast selber schauderte“, bis zwar nur noch „reine Gebilde sichtbar" sind, dafür aber „eine Fläche blos gelegt [wird], so groß, wie ich mir vorher nicht gedacht hatte, und an einer Stelle war mir, als sähe ich unter dem Häutchen die Lunge wallen“ (IV, 307). Einen zweiten Patienten, einen von chronisch wiederkehrenden „Geschwüre[n]“ (IV, 313) befallenen Knaben, kuriert Augustinus dann bereits nicht mehr durch den direkten Eingriff, sondern durch eine Mischung aus Heilwasserbehandlung, Diät und Schulbildung, nach einer ganzheitlichen Methode also, die die Haut als Trägermedium von Identitätsfehlentwicklungen jeder Art begreift und den darauf erscheinenden Symptomen damit jene Authentizität zuweist, die parallel dazu immer mehr auch Augustinus' Aufzeichnungen auf dem Pergament auszuzeichnen beginnt.

Die ,außerordentlich[e]“ Liebeskrankheit der dritten Patientin endlich, der Fürstentochter Isabella, scheint Eustachius letztgültig zu identifizieren - „Aus dieser Wirkung auf ein Frauenherz erkenne ich erst recht, daß Lind Eustachius ist“ (ebd.) - und versetzt Augustinus dadurch in die Lage, die einst , heilloseste Geschichte' ihrerseits zum Instrument einer Heilung zu machen. Die Wunde, die es hier zu schließen gilt, ist, wie ihre Behandlung, rein sprachlicher Art, 
diagnostiziert Augustinus sie doch als einen Riß im familiären Kommunikationskontinuum: „In der Familie wurde von Lind nicht mehr gesprochen“ (IV, 317), seit Isabellas Verliebtheit an den Tag getreten war, berichtet der Obrist, Augustinus aber rät den Eltern im Gegenteil dazu, „daß sie von dem Manne [...] freundlich sprechen“ (IV 320) sollten; erst die Auslassung seines Namens verleiht - ähnlich den ,Pechpflastern' auf der Brustwunde des von ihm operierten Jünglings - der Lücke, die Linds Abreise in Isabellas Gefühlen hinterlassen hat, den Charakter einer möglicherweise gefährlichen Verletzung. Der souveräne Umgang mit Sprache, anhand dessen Augustinus am Ende einer langen Gesprächstherapie ${ }^{36}$ schließlich an der Geschichte des Eustachius Isabellas Krankheit ihrer heilenden Katharsis zuführen kann, zeugt von der Meisterschaft, die er während seiner Niederschrift darin errungen hat, Worte weit über den einst ihn aus der Gefahr des Selbstmords erlösenden ,Satz zu bruchlos kohärenten Flächen zu fügen. Kraft dieser Meisterschaft kann Augustinus Isabellas „Begehren“ (IV, 318) noch vor seiner Bewußtwerdung tilgen und die Frau damit zu einer Verfassung zurückführen, in der sie, wie er ihren Eltern versichert, nunmehr wie ihre Schwestern in ihrer ,natürlichen Empfindung, sobald der rechte Mann kömmt, ihm mit Freuden zum Altare folgen" (IV, 338) werde.

\section{IV}

Das Motiv des Altars, mit dem die letzte Fassung der Mappe hier abbricht, verweist an dieser Stelle zurück auf die Statue der heiligen Margaretha, von der die Erschließung von Augustinus' Aufzeichnungen in der Rahmenerzählung ihren Ausgang nimmt, und damit auf jenes Bildsymbol, an dem die Affinität zwischen Autorschaft und Stiftungswesen in der Mappe auf den ersten Blick am deutlichsten in Erscheinung tritt, gehört doch die Stiftung eines sakralen Bildwerks als Möglichkeit, mit dem Anspruch auf jenseitiges Seelenheil zugleich auch den auf Erhalt und Tradierung des eigenen Namens in der Geschichte zu erwerben, zu den weit zurückreichenden Traditionen vor allem des Katholizismus. ${ }^{37}$ In der Journalfassung der Mappe wird die Verbindung der Statue mit dieser Tradition noch in den Bemerkungen dokumentiert, mit denen

Zum Begriff der Gesprächstherapie in diesem Zusammenhang vgl. Gundel Mattenklott: Sprache der Sentimentalität. Zum Werk Adalbert Stifters. Frankfurt/M. 1973, S. 69ff.

37 Stifter muß spätestens seit seinem Eintritt in das Benediktinerstift Kremsmünster 1818 mit dieser Form des Stiftungswesens vertraut gewesen sein; als Erwachsener ist seine Kenntnis derartiger Werke allein schon durch seine Tätigkeit als Konservator für Oberösterreich seit 1853 belegt, unter anderem durch seinen Einsatz für Restaurierung und Erhalt des berühmten Kefermarkter Altars und der Margarethenkapelle der Stadtpfarrkirche von Steyr. Vgl. Otto Jungmair: Adalbert Stifter als Denkmalpfleger. Linz 1973 (Schriftenreihe des Adalbert-Stifter-Institutes des Landes Oberösterreich 28). 
Augustinus nach Empfang des Auftragswerks dessen Verbindung zu anderen sakralen Plastiken kommentiert:

Ist sie auch nicht so schön wie die Engel und Heiligen, so ich in der Teinkirche gesehen, so ist ja auch der Hausaltar nicht so schön, wie derjenige zu Prag. Die Vergoldung mag gut seyn, die Falten sind sehr gut, eben so der gehobne Fuß. Nun muß der Tischler einen Lindwurm machen, der unter den FuB gehört, daß sie auf ihn trete, wie die auf dem Altarbilde zu Oberplan. $(I, 41)$

Die Buchfassung reduziert diese Unternehmung auf Augustinus' Planung einer Hauskapelle, in der „das Bildniß der heiligen Margarita als Schutzherrin [..] stehen müsse“ (II, 198), um am Ende der Figur des Obristen eine Interpretation in den Mund zu legen, die die von der Journalfassung angedeutete Stellvertreterfunktion für „die geliebte, mit Unmaß angebethete Gestalt“ (I, 100) der Geliebten benennt: „Da ich einmal von euch fort ging, kamen mir bitterliche Thränen in die Augen, weil ich gesehen habe, daß ihr eine heilige Margarita, deren Sinnbild ich gar wohl kenne, auf euren Hausaltar gestellt habt, um euer Herz zu trösten“ (II, 216).

In den beiden letzten Fassungen aber löscht Stifter aus den Binnenerzählungen sowohl die Beschaffung als auch die Deutung der Statue heraus und läßt sie damit gegen den Text der Mappe als eigentlichem Stiftungswerk zurücktreten. Schon in der Rahmenerzählung vertritt die Statue, in ,eine[m] hölzerne[n] dunkle[n] Gang zwischen Schüttboden und Dach“ (IV, 4) aufbewahrt, in ihrer marginalisierten Position von Anfang an die Arbitrarität einer künstlerischer Formgebung, die, sobald sie aus ihrem einstigen Gebrauchszusammenhang herausgelöst wird, nur noch von sich selbst zeugen kann. Entsprechend geht von ihrem Goldüberzug die Aura der Kunstschöpfung, aus der die Farbregie von Augustinus' Aufzeichnungen die Komponente moralischer und erotischer Verführung sorgfältig zugunsten der des therapeutisch-poetischen Heilsstrebens herausfiltern wird, noch gänzlich ungeschieden als „drohender Schein“ (ebd.) aus, der vor jeder Differenzierung auf sein sprachliches Fundament verweist: In in allen vier Fassungen steht die Statue auf einem - in der Journalfassung noch „ungeheuren“, in allen anderen schlicht „großen“ - „Untersatze“",38 an dem wie später an dem ,Satz', der Augustinus aus der Gefahrenzone seiner Selbstmordabsicht bringt, der Text seine eigenen Voraussetzungen reflektiert.

Über die gewissermaßen konstitutionelle Ambivalenz poetischer Rede hinaus steht die vergoldete Fassung der hölzernen Statue für den Reiz der geschlossenen Werkgestalt, wie sie die klassische Literaturästhetik im Namen der Kunstautonomie propagiert hatte. Der Fundort der Statue und die Alterungsspuren an ihrer „vielfach zerschleift[en]“ (I, 12) Vergoldung konnotieren diese Ästhetik als einen Anachronismus, der, obwohl überholt, doch noch immer als Inititalreiz für die Öffnung der Truhe und damit für den Beginn der Lektüre zu fungieren vermag. Der Inhalt der Truhe aber steht bereits in einem Kontrast zur 
Ästhetik der vergoldeten Oberfläche, der um so mehr an Schärfe gewinnt, sobald das Fragmentarische als Möglichkeitsbedingung für die Heilkraft des Schreibens und damit als Grundlage dafür lesbar wird, daß die Mappe zu einem ,Ekstein" zukünftiger Literarhistorie werden kann, überträgt doch die ästhetische Programmierung, anhand derer der Text seine produktive Rezeption einleiten soll, seinem Leser mit der vom Rahmenerzähler präfigurierten Rolle ${ }^{39}$ des Kopisten als Erfinder die Aufgabe, angesichts des Bruchstückcharakters der vorliegenden Materialien seinerseits Augustinus' Rezeptur zur eigenverantwortlichen Fortschreibung des Textes anzuwenden. Wenn nun die Verbindlichkeit dieser Rezeptur solcherart letztendlich allein vom Leser legitimiert werden kann, schon der Rahmenerzähler aber durch Auswahl und $\mathrm{Zu}$ sammenstellung in sie eingreift und die Binnenerzählungen durch den Unterschied zwischen den Schreibpraxen Augustinus' und des Obristen noch der geglückten Anwendung einen erheblichen Ermessensspielraum einschreiben, dann ist dem Projekt der Mappe in Gestalt des impliziten als schöpferischen Lesers eine Unbekannte inhärent, die dieses Projekt konzeptionell auf den Status des Bruchstücks verpflichtet.

Der Kontrast zwischen Statue und Text entbirgt dabei nicht so sehr einen inneren Widerspruch zwischen künstlerischem Anspruch und didaktischer Praxis als vielmehr die gegenseitige Abhängigkeit der einzelnen Elemente, derentwegen sie erst in summa den komplexen Entwurf des Autors als Stifter ergeben. Die meisten Facetten dieses Entwurfs werden vom Text an die Figur des Augustinus angelagert, angefangen vom Bau des Hauses mit der darin enthaltenen Hauskapelle, die die mit dem Hausbau verknüpfte Hoffnung auf Familiengründung anhand der vergoldeten Statue als Anliegen religiös dimensionierten Heilsstrebens sakralisiert, über die Ritualisierung seines Schreibens zu einem in den Dienst dieses Heilsstrebens gestellten Kult und dessen Engführung mit der Heilpraxis des Arztes bis hin zu dem Selbstporträt, das mit seiner Niederschrift potentiell historiographisch verfügbar wird. Schon die beiden gegensätzlichen Figuren Eustachius' und des Obristen allerdings lenken innerhalb der Binnenerzählungen den Blick auf das Bindeglied, dessen Fehlen Augustinus' Schreibprojekt von dem der Mappe selbst unterscheidet: Sowohl der Obrist als auch Augustinus betreiben ihre karitative Arbeit - der eine als väterlicher Mentor, der andere als Arzt -- ohne den Öffentlichkeitsbezug, mit dem die private Initiative erst die gesellschaftliche Bedeutung eines Stiftungswerks erhält, während Eustachius sich umgekehrt durch das publikumsabhängige Selbstverständnis des Berufspoeten den Weg zu einer karitativen oder doch zumindest kulturfördernden Identifikation verstellt.

Der Öffentlichkeitsbezug dagegen, den Adalbert Stifter in der Mappe programmiert, basiert auf der gegenseitigen Abhängigkeit von sozialfähiger Identifikation und literaturgeschichtsfähiger Autorschaft. In dem Maß, in dem der 
Autor der Mappe das ursprünglich zur rein privaten Nutzung geschaffene Gegenstandspaar von Statue und Buch zu einem Ensemble aus Bildwerk und Stiftungsurkunde konfiguriert, das den Reiz künstlerischer Vollendung seiner Konzeption als Bruchstück unterstellt, setzt er seinen Text als ein Stiftungswerk in Szene, das, den Selbstentwurf des Autors unlösbar mit der erfolgreichen Bildung seiner Leser verschränkend, das Heilsstreben des Dichters als karitativ motivierte Kulturationsarbeit programmatisch vergesellschaftet. Gerade dadurch erfüllt der Text am Ende dann auch, was das Bild des ,papiernen Handspiegels' angekündigt hatte: Dem in der Stiftungsurkunde gegebenen Bauplan getreu vielfach gebrochen, aber doch unzweifelhaft als solches erkennbar, entwirft Die Mappe meines Urgroßvaters das Porträt des Autors als Stifter. 